\title{
CHRONIC NICOTINE ATTENUATES BEHAVIORAL AND SYNAPTIC PLASTICITY IMPAIRMENTS IN A STREPTOZOTOCIN MODEL OF ALZHEIMER'S DISEASE
}

\author{
I. M. ESTEVES, ${ }^{a *}$ C. LOPES-AGUIAR, ${ }^{a \dagger}$ \\ M. T. ROSSIGNOLI, ${ }^{a}$ R. N. RUGGIERO, \\ A. C. S. BROGGINI, ${ }^{a, c}$ L. S. BUENO-JUNIOR, ${ }^{a}$ \\ L. KANDRATAVICIUS, ${ }^{a}$ M. R. MONTEIRO, ${ }^{a}$ \\ R. N. ROMCY-PEREIRA ${ }^{\mathrm{b}}$ AND J. P. LEITE \\ ${ }^{a}$ Department of Neuroscience and Behavioral Sciences, Ribeirão \\ Preto Medical School, University of São Paulo (USP), Ribeirão Preto, \\ Brazil \\ ${ }^{\mathrm{b}}$ Brain Institute, Federal University of Rio Grande do Norte \\ (UFRN), Natal, Brazil \\ ${ }^{\mathrm{c}}$ Ernst Strüngmann Institut (ESI) for Neuroscience in \\ Cooperation with Max Planck Society, Frankfurt 60528, Germany
}

\begin{abstract}
Brain glucose metabolism is altered in sporadic Alzheimer's disease (SAD), whose pathologies are reproduced in rodents by intracerebroventricular (icv) infusion of streptozotocin (STZ) in subdiabetogenic doses. The icvSTZ model also culminates in central cholinergic dysfunctions, which in turn are known to underlie both the SAD cognitive decline, and synaptic plasticity impairments. Considering the cognitive-enhancing potential of chronic nicotine ( $\mathrm{Nic}$ ), we investigated whether it attenuates icvSTZ-induced impairments in recognition memory and synaptic plasticity in a cognition-relevant substrate: the hippocampal CA1-medial prefrontal cortex (mPFC) pathway. Rats treated with icv-STZ were submitted to a chronic Nic regime, and were evaluated for recognition memory. We then examined long-term potentiation (LTP), paired-pulse facilitation (PPF) under urethane anesthesia, and brains were also evaluated for hippocampus-mPFC cell density. We found that Nic treatment prevents icv-STZ-induced disruptions in recognition memory and LTP. STZ did not precipitate neuronal death, while Nic alone was associated with higher neuronal density in CA1 when compared to vehicle-injected animals. Through combining behavioral, neurophysiological, and neuropathological observations into the Nic-STZ interplay, our study reinforces that cholinergic treatments are of clinical importance against early-
\end{abstract}

\footnotetext{
${ }^{*}$ Corresponding author. Address: Department of Neuroscience and Behavioral Sciences, Ribeirão Preto Medical School, University of São Paulo (USP), Av. Bandeirantes 3900, CEP 14049-900 Ribeirão Preto, SP, Brazil.

E-mail address: ime_br@yahoo.com (I. M. Esteves).

$\dagger$ Present Address: Neuroscience Center, Department of Physiology and Biophysics, Federal University of Minas Gerais (UFMG), Minas Gerais, Brazil.

Abbreviations: HFS, high-frequency stimulation; icv, intracerebroventricular; LTP, long-term potentiation; mPFC, medial prefrontal cortex; Nic, nicotine; PPF, paired-pulse facilitation; SAD, sporadic Alzheimer's disease; STZ, streptozotocin.
}

stage Alzheimer's disease and mild cognitive impairments. (c) 2017 IBRO. Published by Elsevier Ltd. All rights reserved.

Key words: Alzheimer's disease, streptozotocin, nicotine, recognition memory, synaptic plasticity, long-term potentiation.

\section{INTRODUCTION}

Dysfunctional insulin signaling in the brain triggers the sporadic type of Alzheimer's disease (SAD) (de la Monte and Tong, 2014), which is characterized by decreased brain glucose metabolism (Hoyer, 1998; Frölich et al., 1998; Watson and Craft, 2003). Disturbances in central insulin signaling have also been shown to affect amyloid-beta $(A \beta)$ levels and tau protein hyperphosphorylation (Hoyer, 2004; Salkovic-Petrisic et al., 2009), supporting the notion that SAD may be considered to be the brain type of diabetes (Hoyerm 2002; de la Monte, 2014). The intracerebroventricular (icv) administration of the diabetes-inducing drug streptozotocin (icv-STZ) has been investigated as a non-transgenic model of SAD (Lester-Coll et al., 2006; Salkovic-Petrisic and Hoyer, 2007). Subdiabetogenic doses of icv-STZ (1-3 mg/kg) mimic features of human SAD, such as metabolic dysfunctions (Hoyer and Lannert, 2007), brain insulin resistance associated with tau protein hyperphosphorylation (Grünblatt et al., 2007; Barilar et al., 2015), A $\beta$-like aggregation in meningeal vessels (Salkovic-Petrisic et al., 2011), cholinergic deficits (Blokland and Jolles, 1993), and memory impairments (Lannert and Hoyer, 1998; Agrawal et al., 2011). Taking into consideration that STZ does not cross the blood-brain barrier, icv-STZ decrease cerebral glucose uptake without altering blood glucose level (Grieb, 2016). However, it remains to be investigated whether the icv-STZ model can mimic functional connectivity alterations observed in SAD (Morgen and Frölich, 2015).

The earliest pathological events in Alzheimer's disease are thought to be the degeneration of basal forebrain cholinergic neurons, whose severity could positively correlate with memory impairments (Auld et al., 2002; Schliebs and Arendt, 2011). This finding has led to pro-cognitive therapeutic strategies via acetylcholine (ACh) neurotransmission, either by enhancing its endogenous level, or by reducing the activity of choli- 
nesterase inhibitors (Anand et al., 2014). Modulating cholinergic receptors is another attractive approach. In vivo studies have indicated that agonists of muscarinic acetylcholine receptors (mAChRs) reverse cognitive impairments, while decreasing tau protein phosphorylation and $A \beta$ processing (Fisher, 2012). Because nicotinic agonists are known as memory enhancers (Leiser et al., 2009; Levin, 2012), nicotinic acetylcholine receptors (nAChRs) are also potential targets against cognitive decline in Alzheimer's disease (Wallace and Bertrand, 2013). The $n A C h R$ agonist nicotine (Nic) is of particular interest, given its pro-cognitive effects on learning, memory, and attention (Kenney and Gould, 2008; Changeux, 2010; Gould and Leach, 2014), as well as its modulatory influence on synaptic plasticity and glutamatergic transmission in cortico-limbic circuits (Lambe et al., 2003; Poorthuis and Mansvelder, 2013). Nic treatments could, therefore, modulate cognitive and neurophysiological variables in animal models of Alzheimer's disease, which requires further investigation.

Synaptic plasticity is thought to be a cellular model of learning and memory (Bliss and Collingridge, 1993; Citri and Malenka, 2008). Limbic-cortical synaptic plasticity can be dysfunctional in prodromal Alzheimer's disease, which could explain its mild cognitive alterations (Scheff et al., 2006; Arendt, 2009). In this context, the hippocampal CA1-medial prefrontal cortex (mPFC) communication is prone to long-term plasticity (Lopes-Aguiar et al., 2008, 2013; Takita et al., 2013), is implicated in working memory (Spellman et al., 2015; Blot et al., 2015) and memory consolidation (Laroche et al., 2000; Taylor et al., 2016; Maingret et al., 2016; Jadhav et al., 2016; Barker et al., 2017). Thus, synaptic plasticity in this circuit could be increasingly altered as Alzheimer's disease develops, which can be experimentally studied using the icv-STZ model of SAD. Given the potential interplay between $S A D$ and nicotinic modulation, we used rats to investigate the effects of icv-STZ - with or without chronic Nic treatment - on recognition memory, as well as CA1- mPFC synaptic plasticity. We also evaluated how these pharmacological manipulations affect cell density in the mPFC and hippocampus.

\section{EXPERIMEMTAL PROCEDURES}

\section{Animals}

Male Wistar rats aged between 35 and 42 days (140$160 \mathrm{~g}$ ) were housed in standard rodent cages under $24^{\circ} \mathrm{C}$ and 12-h light/dark cycle (lights on at $7 \mathrm{AM}$ ) with free access to food and water. All behavioral experiments were performed between $7 \mathrm{AM}$ and $7 \mathrm{PM}$. Procedures were in accordance with the Brazilian Council for Animal Experimentation (CONCEA) guidelines, and were approved by the Ethics Committee of the Ribeirão Preto Medical School, University of São Paulo. These guidelines also abide by the National Institutes of Health rules for the care and use of laboratory animals (NIH Publications No. 8023, revised 1978).

A total of 40 rats were employed (starting with 10 animals per group), 12 of which were excluded because of technical issues: usually, electrical noise, inconsistent evoked field postsynaptic potentials (fPSP), and loss of coronal specimens during the antigenic retrieval process. Such issues explain the variation in group size.

\section{STZ injection and Nic treatment}

Animals were anesthetized with ketamine and xylazine $(0.75$ and $0.38 \mathrm{mg} / \mathrm{kg}$ intraperitoneal, then 0.5 and $0.25 \mathrm{mg} / \mathrm{kg}$ intramuscular) and placed in a stereotaxic frame for bilateral icv injection of STZ (Sigma-Aldrich, USA). We used the following bregma-referenced coordinates: $0.5 \mathrm{~mm}$ posterior, $1.4 \mathrm{~mm}$ bilateral, $3.5 \mathrm{~mm}$ ventral from dura-mater, according to Paxinos and Watson (2007). STZ (3 mg/kg) was dissolved in $4 \mu \mathrm{L}$ of artificial cerebrospinal fluid (aCSF; in mM $1.2 \mathrm{CaCl}_{2}, 2.7$ $\mathrm{KCl}, 1.0 \mathrm{MgCl}_{2}, 135.0 \mathrm{NaCl}$ ). Each hemisphere received $2 \mu \mathrm{L}$ of this solution through a $10 \mu \mathrm{L}$ microsyringe (Hamilton, USA) connected to a polyethylene tube $(30 \mathrm{~cm})$ and a gingival needle (13 mm, 30G; Injex, Brazil) at $0.5 \mu \mathrm{L} / \mathrm{min}$ flow (Barilar et al., 2015). Control animals received aCSF instead. The surgery was concluded with scalp suture, subcutaneous flunixin meglumine $(2.5 \mathrm{mg} / \mathrm{kg}$; analgesic, anti-inflammatory, antipyretic) and intramuscular benzylpenicillin benzathine $(0.2 \mathrm{ml} / \mathrm{kg}$; antibiotic).

Rats were allowed to recover for two days before the chronic Nic treatment. This decision was based on Santos et al. (2012), who reported working memory disruptions three hours after icv-STZ injection, followed by degenerative processes already at day 1 post-injection. Nevertheless, all of our subjects were showing normal behavioral signs (including eating and drinking) at day 2 post-STZ, and care was taken to minimize their suffering.

For the chronic Nic treatment, we used the (-)nicotine hydrogen tartrate salt (Sigma-Aldrich, USA) dissolved in sterile saline to a freebase concentration of $50 \mathrm{mg} / \mathrm{mL}$. This solution was intraperitoneally injected $(1 \mathrm{mg} / \mathrm{kg})$ once per day over 20 days in STZ and aCSF animals (STZ-Nic and aCSF-Nic groups, respectively). Intraperitoneal saline was used for control (STZ-Sal and aCSF-Sal groups) (Fig. 1A). This Nic dose $(1 \mathrm{mg} / \mathrm{kg}$ ) is based on studies showing that chronic Nic prevents the effects from amyloid beta, and reduces the CSF levels of the amyloid precursor protein (Utsuki et al., 2002; Alkadhi et al., 2010). Furthermore, this dose did not induce visible behavioral abnormalities, such as seizurelike tremors, differently from a higher dose $(3 \mathrm{mg} / \mathrm{kg})$ we tested in a pilot study.

\section{Behavioral assessment}

A 65-day washout was allowed between the Nic regime and the behavioral testing period (Fig. 1A), which in turn lasted three days. This delay was meant to exclude withdrawal symptoms, and to evaluate Nic effects over an extended period. The first behavioral measurement was the locomotion on a white-floored open-field arena $(46 \times 46 \mathrm{~cm})$ bounded by transparent acrylic walls and infrared sensors (Insight, Brazil). Beam breaks were collected over a 15-min period for analysis in 3-min bins. Our objective was to rule out locomotor alterations prior to the object recognition test. 
A

B

Baseline and LTP monitoring

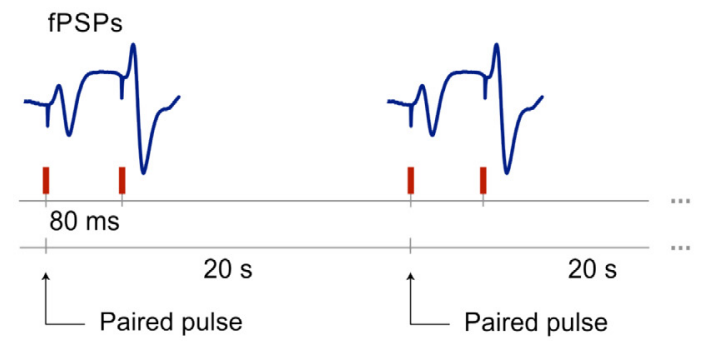

HFS

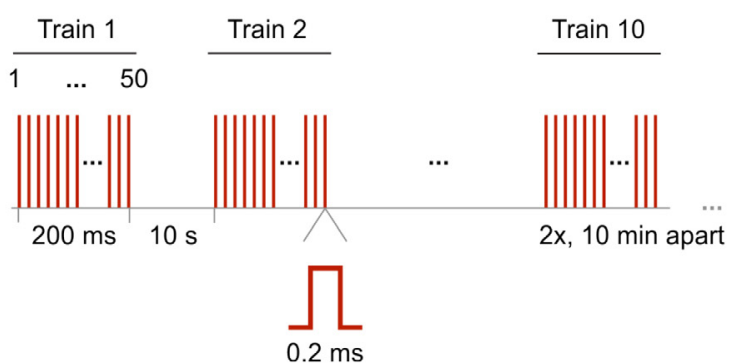

Fig. 1. Experimental design and stimulation procedures. (A) Once recovered from the icv injection (streptozotocin, STZ, or artificial cerebrospinal fluid, aCSF), chronic treatment was performed (nicotine, Nic, or saline, Sal). A 65-day washout was allowed, and the rats were submitted to a battery of behavioral assessments (open-field locomotion and novel object recognition). At completion of the behavioral testing, the rats were anesthetized with urethane and submitted to acute electrophysiology in vivo. (B) Electrophysiological sessions consisted of a 30-min baseline, high-frequency stimulation (HFS) for induction of long-term potentiation (LTP), and an additional 240-min recording. Paired pulses (80-ms inter-pulse interval) were delivered into hippocampal CA1 every $20 \mathrm{~s}$ while recording field post-synaptic potentials (fPSP) from the medial prefrontal cortex (mPFC), except during HFS.

On the following two days, we employed the novel object recognition (NOR) paradigm. It consisted of three phases: habituation on day 1 , and training followed by test on day 2. For habituation, animals were allowed to roam on a lab-made, black-floored wooden box $(30 \times 30 \mathrm{~cm})$ for $15 \mathrm{~min}$. For training, the rats were allowed to explore two identical objects (yellow cylindrical cups with blue lids, 3-cm diameter - 4-cm height) during $4 \mathrm{~min}$, and were then returned to their home cages. After a 20-min interval, the animals were placed back onto the arena for the test phase, in which they were exposed to a novel object (white cylindrical cups with orange lids, $3-\mathrm{cm}$ diameter, $3-\mathrm{cm}$ height) and the familiar one (same from the training phase) for an additional 4 min (Bevins and Besheer, 2006; Warburton et al., 2013). Sessions were filmed by a webcam on the top of the box and all objects were wiped with $70 \%$ ethanol after each session. The object exploration was calculated as the percentage of time spent at each object divided by the time exploring both objects. Similarly, recognition index was calculated as the time spent at the novel object divided by the time exploring both objects. The discrimination ratio, in turn, was calculated as the difference between novel and familiar object exploration divided by the time exploring both objects. Quantification of object exploration time was performed by a blind observer.

\section{Electrophysiology}

On day 91 (Fig. $1 \mathrm{~A}$ ), rats were anesthetized with urethane $(1.2 \mathrm{mg} / \mathrm{kg}$ i.p. in sterile saline; Sigma-Aldrich, USA) and placed back on the stereotaxic frame for electrode implantation with body temperature maintained at 37 $\pm 0.5^{\circ} \mathrm{C}$ through a heating pad (Insight, Brazil). When necessary, the level of anesthesia was maintained with supplementary injections of the anesthetic $(10 \%$ of the initial dose) after checking the tail pinch reflex. Once the skull was exposed, two bregma-referenced holes were drilled (Paxinos and Watson, 2007): over the prelimbic $(\mathrm{PL})$ region of $\mathrm{mPFC}(3.0 \mathrm{~mm}$ anterior, $0.5 \mathrm{~mm}$ lateral, 3.1-3.4 $\mathrm{mm}$ ventral from dura-mater) and the ipsilateral dorsal region of CA1 $4.7 \mathrm{~mm}$ posterior, $4.0 \mathrm{~mm}$ lateral, 2.5-2.8 mm ventral), each receiving a monopolar recording electrode. A third ipsilateral hole was drilled over the intermediate region of CA1 $(5.7 \mathrm{~mm}$ posterior, $4.6 \mathrm{~mm}$ lateral, $2.5-2.8 \mathrm{~mm}$ ventral) for the bipolar stimulating electrode. Lastly, a fourth hole was drilled over the contralateral parietal cortex (no precise coordinate) to implant a microscrew for recording reference.

The bipolar electrode was made from twisted wires (Teflon-coated tungsten, $60 \mu \mathrm{m}$ bare diameter, $\sim 500 \mu \mathrm{m}$ inter-pole distance) for CA1 stimulation with a pairedpulse protocol (monophasic square pulses, 200- $\mu \mathrm{s}$ duration each pulse, $80-\mathrm{ms}$ inter-pulse interval, $0.05 \mathrm{~Hz}$ 
rate), while recording basal and facilitated field postsynaptic potentials (respectively fPSP1 and fPSP2) from the mPFC monopolar electrode (Teflon-coated tungsten, $60-\mu \mathrm{m}$ diameter) (Fig. 1B). Electrical pulses were generated from an S88X stimulator and photoelectrically isolated (PSIUX, Grass Technologies, West Warwick, $\mathrm{RI}, \mathrm{USA})$. Analogical signals were amplified, filtered $(\times 100, \quad 0.3-3 \mathrm{kHz}, \quad$ P55 pre-amplifier, Grass Technologies), digitized $(10 \mathrm{kHz}, \quad$ PowerLab, AD Instruments), and recorded on LabChart 7.2 software (ADInstruments, Australia).

Before the experiment, the mPFC and intermediate CA1 implants were finely adjusted for optimal fPSP evoking and, therefore, electrophysiological validation of electrode positioning. We then delivered pulses at increasing intensities $(60-500 \mu \mathrm{A}, 0.05 \mathrm{~Hz})$ to probe the input-output curve, and to identify the stimulus intensity that would be used in the experiment (i.e., the intensity able to evoke fPSP amplitudes at $\sim 50 \%$ of the maximum input-output amplitude).

We then started the experiment, comprising a 30-min baseline recording, long-term potentiation (LTP) induction, and an additional 240-min recording (Fig. 1B). Paired pulses were delivered throughout this timeline for probing the paired-pulse facilitation (PPF: fPSP2/fPSP1 amplitude ratio), except during LTP induction, when stimulation parameters were set to a high-frequency stimulation (HFS) protocol. It consisted of two series (10 min apart) of 10 trains (10 s apart), each train with 50 pulses at $250 \mathrm{~Hz}$. LTP was evaluated in $10 \mathrm{~min}$ averaged fPSP amplitudes, which were plotted as ratios from the baseline mean amplitude (Lopes-Aguiar et al., 2008).

\section{Cell density analysis}

After electrophysiological recordings, rats were perfused with saline followed by phosphate-buffered $4 \%$ paraformaldehyde. Brains were removed from the skull, dehydrated in $70 \%$ ethanol, and embedded in paraffin for microtome sectioning $(8 \mu \mathrm{m})$ and hematoxylin and eosin staining (Laborclin, Brazil). Coronal specimens were obtained from the following anterior-posterior segments: +4.68 to $+2.76 \mathrm{~mm}$ (prefrontal cortex), and -4.44 to $-4.80 \mathrm{~mm}$ (intermediate hippocampus) (Paxinos and Watson, 2007). Images from the PL area of the mPFC, and CA1 of the hippocampus were captured through a video monochrome charge-coupled device camera (Model 2400, Hamamatsu Photonics, Tokyo, Japan) attached to a microscope (Model BX60, Olympus, Tokyo, Japan). Images were averaged and digitized using the Scion Image frame grabber, and were then analyzed using the public-domain software Image $(\mathrm{NIH}$, Bethesda, $\mathrm{MD}, \mathrm{USA}$ ). Five squares of $50 \times 50 \mu \mathrm{m}$ were randomly placed on each analyzed brain area (right and left hemispheres) from all animals of each group, and then averaged after the counting. We performed neuron counts (neurons per cubic millimeter) estimated at $200 \times$ magnification using a morphometric grid methodology and Abercrombie's correction (Abercrombie, 1946) as previously described and extensively used by our group and others (Andrade-Valença et al., 2008; Kandratavicius et al.,
2013, 2014; Rodrigues et al., 2015; Wolf et al., 2015). Neurons were distinguished from glial cells by their clearly distinct morphological appearance. The experimenter was blinded to group allocation.

\section{Statistical analysis}

One-way ANOVA was used to compare averaged (i.e., single value) variables between groups, namely: open field total distance, recognition index, baseline fPSP properties (latency, amplitude and PPF), average power spectra bands, and cell density. Two-way ANOVA was used to compare repeated measure variables between groups over time: open field data, discrimination ratio, input-output curve, and time dependent power spectra bands. Tukey's post hoc comparisons were made when ANOVA returned significant effects at the $p<0.05$ criterion.

\section{RESULTS}

\section{Locomotor activity is not altered by Nic or STZ}

During the chronic Nic treatment, increased grooming and locomotion was observed only within 5 min after each injection. However, spontaneous activity in the open field test, i.e., 65 days after the Nic treatment, did not differ among groups, either by measuring the total (whole 15-min session) (Fig. 2A $A_{1}$ ) or the binned (3-min) distance traveled (Fig. 2A $\mathrm{A}_{2}$ ).

\section{Nic prevents STZ-induced recognition memory deficits}

Performance in the NOR task showed that STZ rats had a significant impairment in recognition memory, which was reverted by the chronic Nic treatment. Recognition indices of STZ-Sal rats were at least $25 \%$ lower than those of other groups $\left(F_{(3,24)}=12.643, p<0.001\right)$ (Fig. 2B $\mathrm{B}_{1}$ ). The same can be seen in the discrimination ratio, which revealed no preference of STZ-Sal rats for either object during both training and test phases. Lastly, aCSF-Nic and STZ-Nic discrimination ratio were similar to the aCSF-Sal group (training vs. test: $\left.F_{(1,24)}=48.261, \quad p<0.001 ; \quad F i g .2 B_{2}\right)$. All groups explored both objects equally during the training phase. However, in the test phase only STZ-Sal animals did not show differences in the exploration of object $A$ and $B$, while others groups revealed an increased exploration of the novel object $B$ (training $A$ vs. test $B, p<0.001$; Fig. $\left.2 \mathrm{~B}_{3}\right)$.

\section{STZ diminishes LTP without altering PPF, and Nic attenuates the effect}

No significant differences in the input-output curve, baseline fPSPs latency, or baseline fPSPs amplitude were found among groups (Fig. 3), indicating that the basal hippocampal CA1-mPFC neurotransmission was not affected by any drug treatment prior to the synaptic plasticity experiment. In agreement with the literature, a negative peak at 14-17-ms latency from each pulse characterized all fPSP (Laroche et al., 1990; Takita 
$\mathbf{A}_{1}$

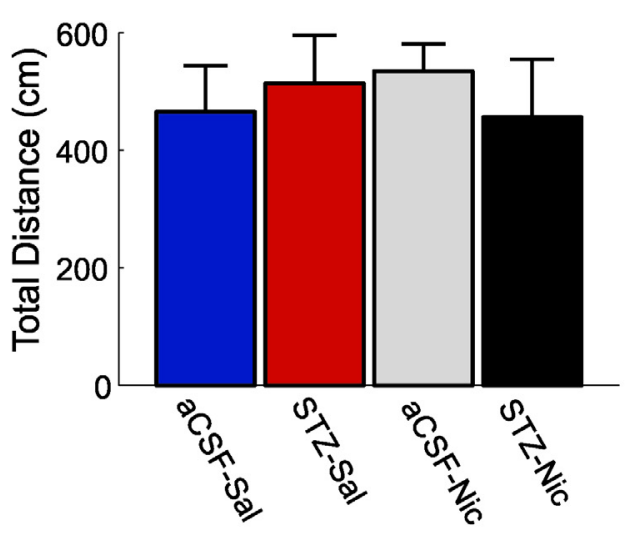

B

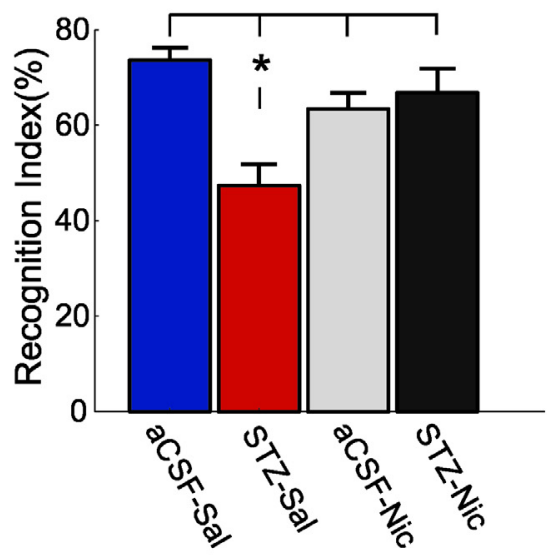

$A_{2}$

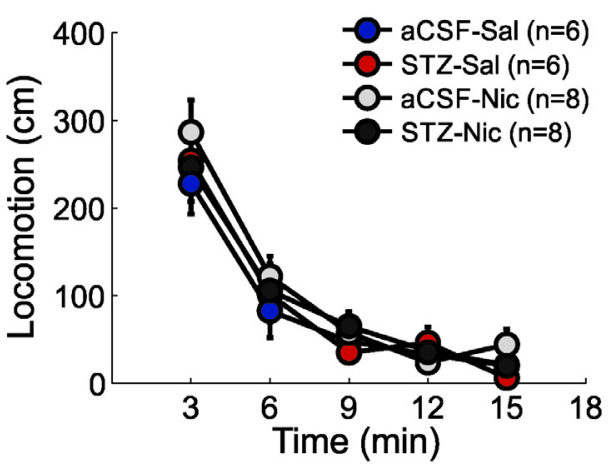

$B_{2}$

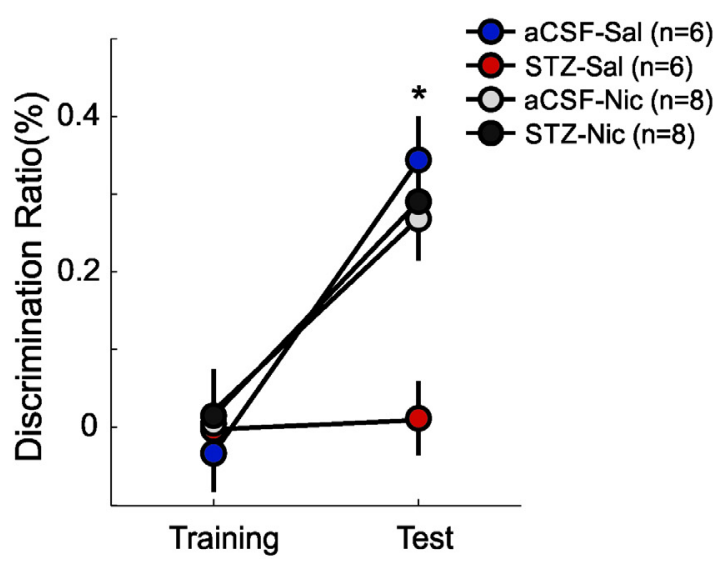

$\mathrm{B}_{3}$

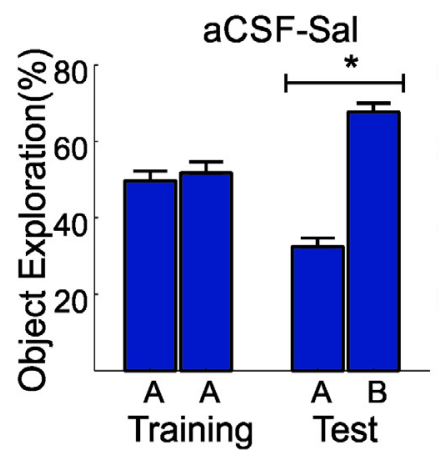

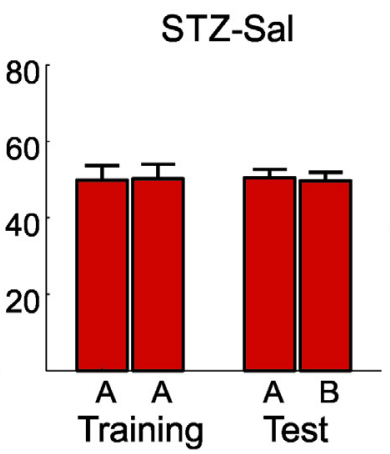

STZ-Nic
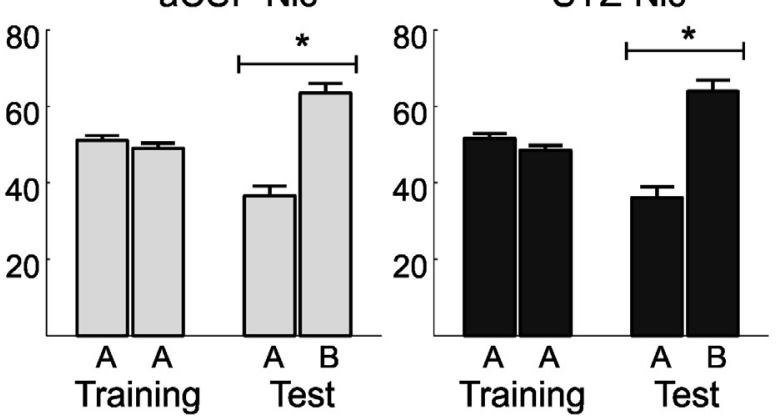

Fig. 2. Effects of streptozotocin (STZ) and nicotine (Nic) on locomotor activity and novel object recognition (NOR). ( $\mathrm{A}_{1}$ ) Neither STZ nor Nic affected the total distance traveled, as measured in the open-field test. $\left(A_{2}\right)$ Locomotor activity throughout 3-min bins indicates that all four groups explored less over time $(p<0.001)$. (B) Detrimental effects of STZ on recognition memory were reverted by Nic. $\left(\mathrm{B}_{1}\right)$ Recognition index $\left({ }^{\star} p=0.002\right)$. $\left(\mathrm{B}_{2}\right)$ Discrimination ratio $\left({ }^{*} p<0.001\right)$. $\left(\mathrm{B}_{3}\right)$ Training vs. test object exploration percentages of each experimental group $\left({ }^{\star} p<0.001\right)$. Values expressed as mean \pm standard error.

et al., 1999) (Fig. 3A, D). The average baseline PPF ratio (fPSP2/fPSP1) was of $2.47 \pm 0.14$ across all groups, and the fPSP1 amplitudes, in particular, were always above $150 \mu \mathrm{V}$ (Fig. 3C-E).

fPSPs and PPF amplitudes of aCSF-Sal animals were compared with the remaining groups in order to investigate time-dependent effects of STZ and chronic Nic in LTP (Fig. 4). Our results show that STZ decreased induction and maintenance of fPSP1 LTP by at least $30 \%$ (treatment vs. time interaction:
$\left.F_{(26,260)}=3.605, p<0.001\right)$. A similar LTP reduction of at least $25 \%$ was found in fPSP2 amplitudes (treatment vs. time interaction: $\left.F_{(26,260)}=2.763, p<0.001\right)$. We also observed that STZ did not affect PPF when comparing STZ-Sal and aCSF-Sal rats (Fig. 4-Left).

Interestingly, chronic Nic reversed the LTP effect caused by STZ, as seen in the fPSP1 results from the STZ-Nic group. In fact, 50 min after HFS there were still no differences in fPSP1 amplitude between STZ-Nic and aCSF-Sal animals. During the initial $50 \mathrm{~min}$, STZ-Nic vs. 
A

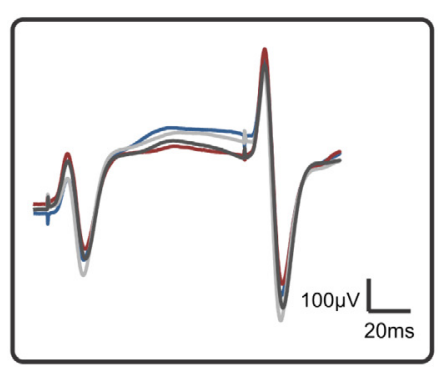

B

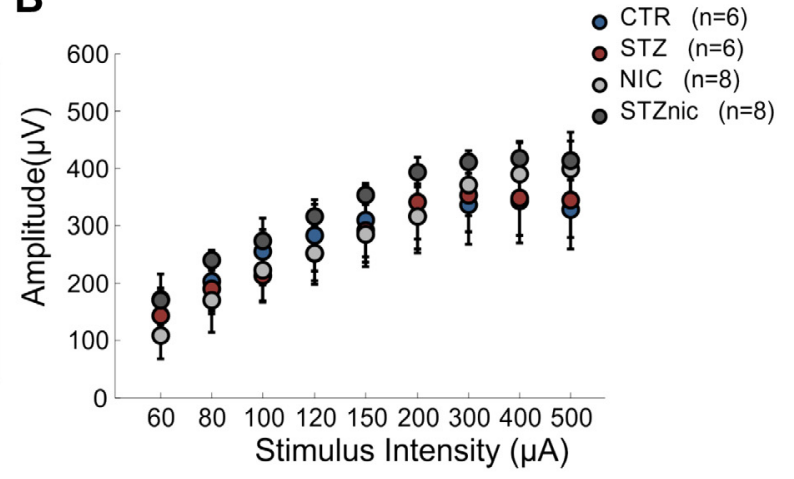

C

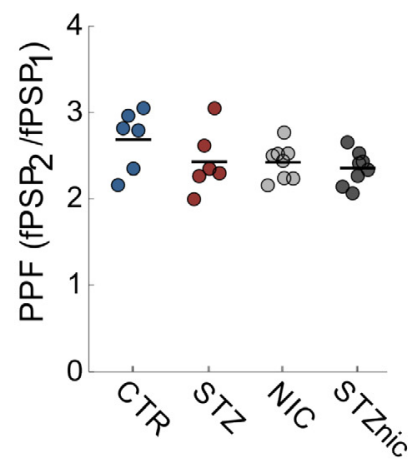

D

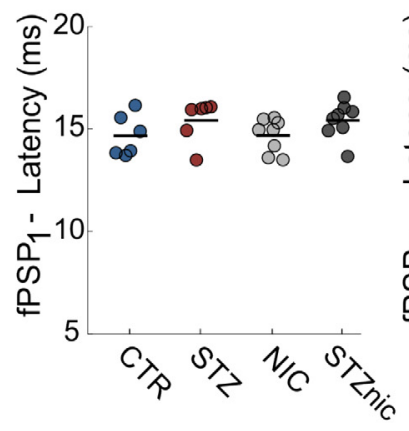

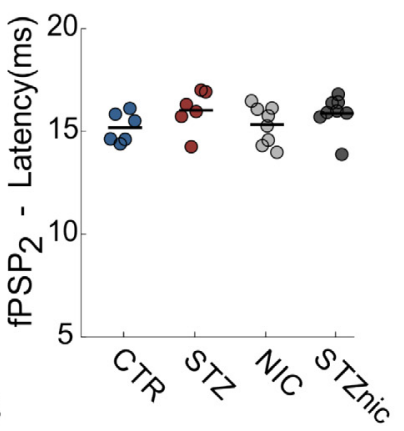
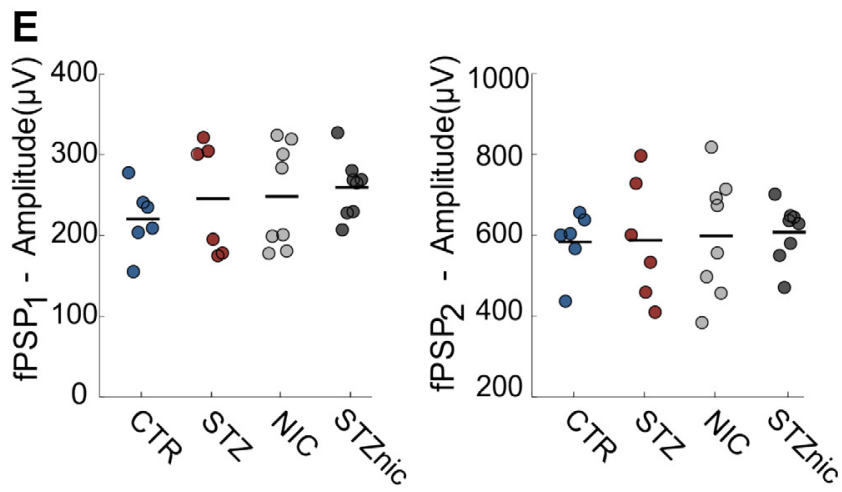

Fig. 3. Field postsynaptic potentials (fPSP1 and fPSP2) properties recorded from the medial prefrontal cortex (mPFC). (A) Averaged fPSP1 and fPSP2. (B) Input-output curves showing no significant differences among groups. Values expressed as mean \pm standard error. (C) Baseline pairedpulse facilitation (PPF) in the mPFC. (D) Baseline fPSP1 and fPSP2 latencies. (E) Baseline fPSPS1 and fPSPS2 amplitudes. No differences were found among groups. Values expressed as mean and dispersion.

aCSF-Sal differences were about 10\% lower than between STZ-Sal and aCSF-Sal (treatment vs. time interaction: $\left.F_{(26,286)}=2.796, p<0.001\right)$. Likewise, STZNic vs. aCSF-Sal comparisons regarding fPSP2 and PPF returned no significant differences (Fig. 4-middle). Nic treatment, per se, did not affect LTP or PPF when comparing aCSF-Nic and aCSF-Sal groups (Fig. 4-right).

When STZ-Nic rats were compared to STZ-Sal ones, we observed that Nic treatment enhanced LTP induction and maintenance of both fPSP1 (effect of treatment: $F_{(1,286)}=8.061, \quad p=0.015$ ) and fPSP2 (effect of treatment: $\left.F_{(1,286)}=9.302, p=0.015\right)$ (Fig. 5A, B-right). We also found that interaction effect from fPSP2 data (treatment vs. time interaction: $F_{(26286)}=1.693$, $p=0.021$ ) (Fig. 5B-left). Additionally, Nic treatment did not affect PPF when comparing STZ-Sal and STZ-Nic rats (Fig. 5C).

\section{Chronic Nic prevents neuronal loss in CA1}

Cell density in CA1 and the PL region of $\mathrm{MPFC}$ showed no differences between STZ and aCSF-Sal animals (Fig. 6). However, aCSF-Nic rats showed a significantly higher cell density in CA1 when compared with other groups $\left(F_{(3,17)}=6.519, p<0.05\right)$. This finding suggests that chronic Nic exerted an STZ-unrelated neuroprotective effect against age-related cell loss in CA1. Increased neuron density was also observed in the mPFC of
aCSF-Nic animals, as we found a significant difference between them and STZ-treated animals $\left(F_{(3,17)}=4.887\right.$, $p<0.05$; Fig. 6B).

\section{DISCUSSION}

Through employing a straightforward behavioral paradigm followed by in vivo electrophysiology, our study reveals detrimental effects of icv-STZ to recognition memory, as well as hippocampal-prefrontal LTP. Noteworthy, we demonstrated that chronic Nic treatment prevents these STZ-induced dysfunctions.

Our findings are consistent with the literature concerning behavioral aspects of $S A D$ rodent models (Lannert and Hoyer, 1998). Shoham et al. (2007) and Espinosa et al. (2013) have reported recognition memory impairments in icv-STZ-treated rats, and a comparative study between rodent models of SAD (Chen et al., 2013) has shown that the icv-STZ model is even more detrimental to short-term memory than the transgenic 3xTg-AD mouse model. In line with the icv-STZ impact on cognition, spatial discrimination impairments in STZtreated animals were shown to correlate with reduced choline acetyltransferase (ChAT) activity in the hippocampus (Blokland and Jolles, 1993; Prickaerts et al., 1999). Because of the cholinergic involvement in both cognition and cortico-limbic plasticity (Poorthuis and Mansvelder, 2013; Gould and Leach, 2014), our findings are further 
A

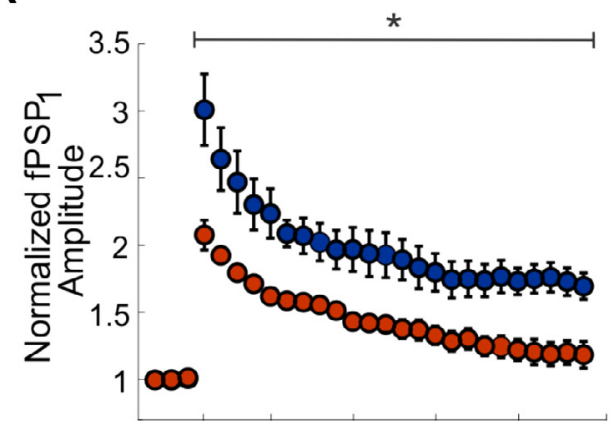

B

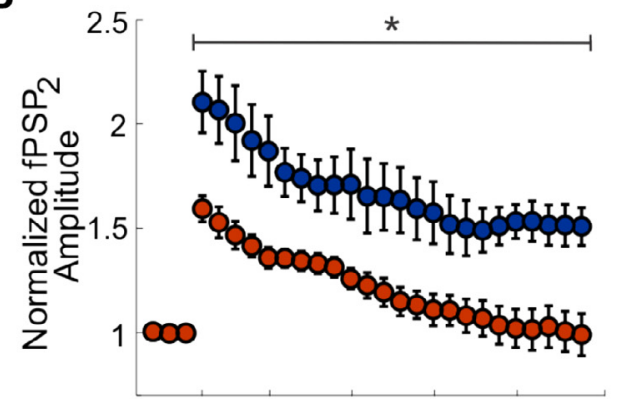

C

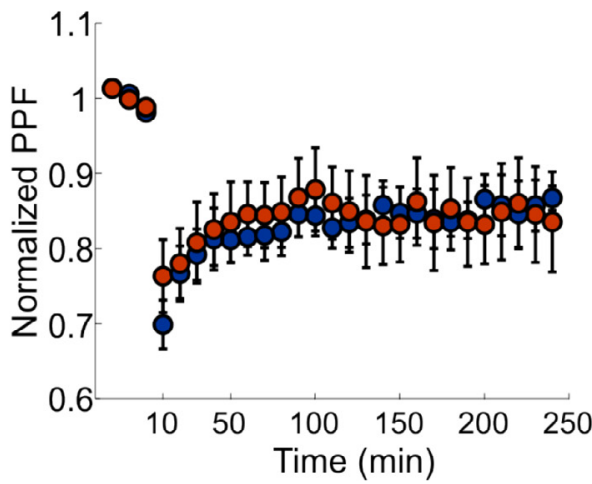

aCSF-Sal $(n=6)$

STZ-Sal $(n=6)$ O aCSF-Nic $(n=8)$

STZ-Nic $(n=8)$
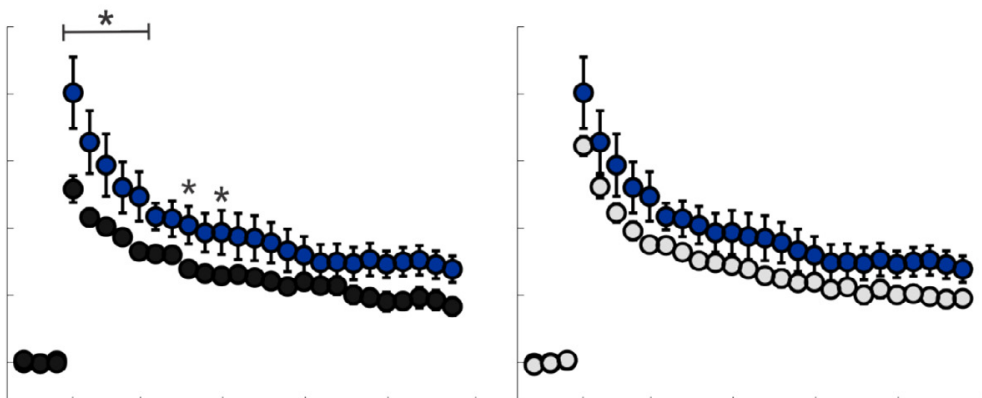

$\infty$
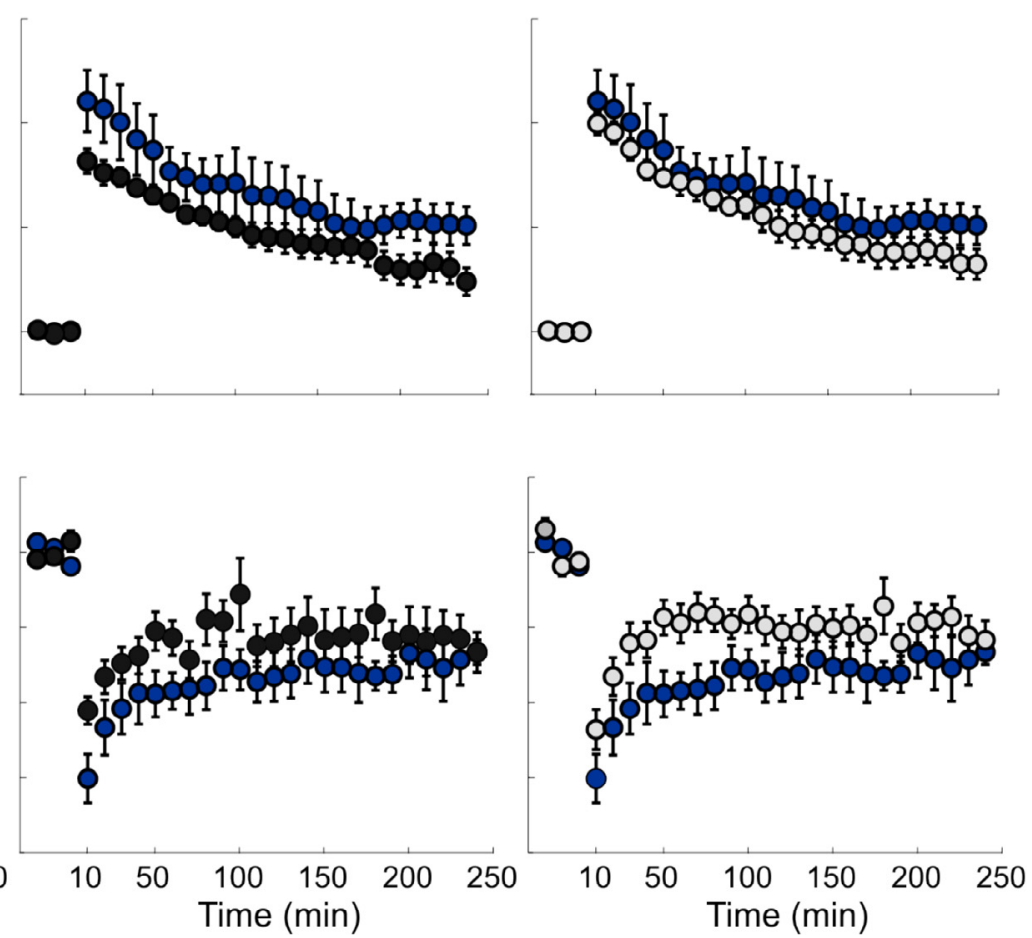

Fig. 4. Field postsynaptic potentials (fPSP1 and fPSP2) and paired-pulse facilitation (PPF) recorded from medial prefrontal cortical (mPFC) during long-term potentiation (LTP). Streptozotocin (STZ) weakened the LTP induction and maintenance, as measured from the amplitudes of fPSP1 (A, left) and fPSP2 (B, left; $\left.{ }^{*} p<0.05\right)$. (C, left) In turn, PPF was not affected by STZ. The middle graphs follow the same organization, this time showing that nicotine (Nic) treatment attenuated the STZ effects on LTP, as measured from both fPSPS1 and fPSP2 amplitudes. The right graphs contain direct comparisons between STZ-untreated groups, showing that Nic, per se, did not affect LTP in a significant manner. Values expressed as mean \pm standard error.

linking behavior and neurophysiology in the icv-STZ model.

It has been hypothesized that LTP-like alterations of synaptic efficacy underlie memory consolidation processes at the systems level (Takeuchi et al., 2013). Particularly, the hippocampus and prefrontal cortex act in synchrony during spatial working memory tasks and are reactivated during rest or non-REM sleep, supporting episodic memory consolidation (Maingret et al., 2016; Jadhav et al., 2016; Barker et al., 2017). Thus, synaptic plasticity in the CA1-mPFC pathway is a possible substrate for episodic memory storage (Laroche et al., 2000). To our knowledge, the present work is the first to demonstrate that icv-STZ reduces the hippocampal- prefrontal LTP in vivo with no significant effects on the short-term synaptic plasticity. Synaptic dysfunctions in animal models of Alzheimer's disease have been well addressed in transgenic models (Chakroborty et al., 2012; Sancheti et al., 2013; Clark et al., 2015). Additionally, Xu et al. (2014) have reported that icv-STZ decreases the dendritic spine density, which was in turn associated with alterations in spatial memory and hippocampal LTP in vitro. As our study differentiates between affected LTP and unaffected PPF, we suggest that both the icv-STZ model and human SAD may present postsynaptic - rather than presynaptic - plasticity dysfunctions. This would be consistent with Shonesy et al. (2012), which have indicated that brain insulin resistance 
A
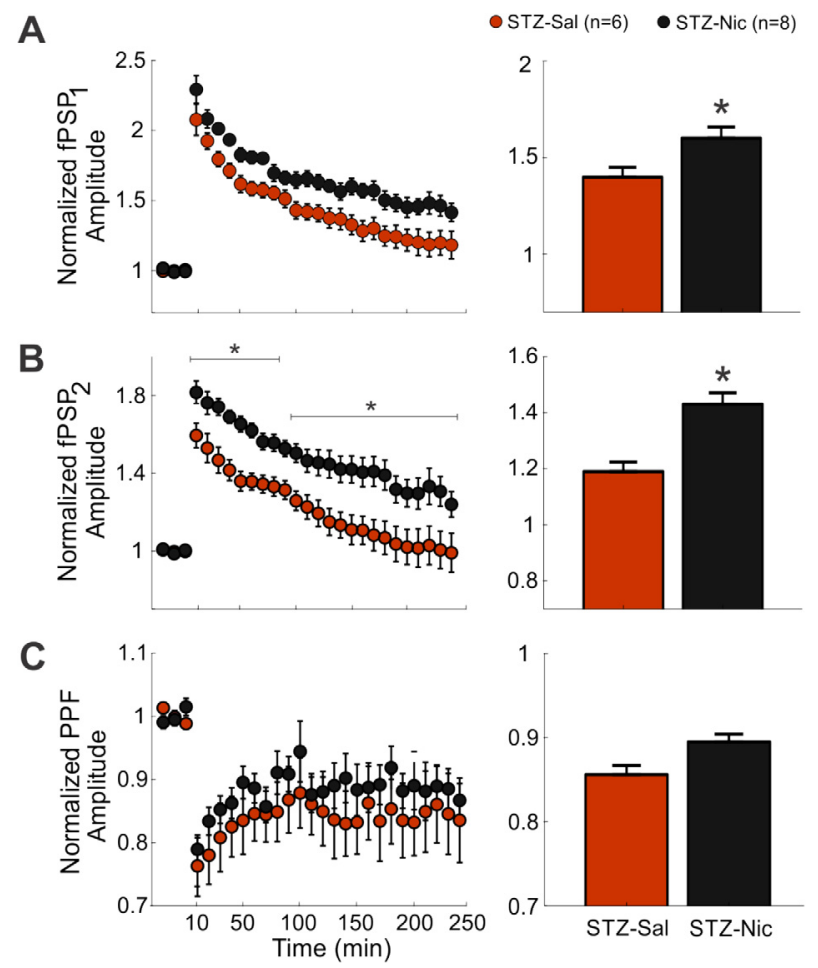

Fig. 5. Effects of nicotine (Nic) treatment on streptozotocin (STZ) rats on field postsynaptic potentials (fPSP1 and fPSP2) and pairedpulse facilitation (PPF). Direct comparisons between STZ-treated groups additionally show that nicotine (Nic) attenuated the STZ effects on long-term potentiation (LTP), as measured from fPSP1 and fPSP2 amplitudes (A, B). (C) In turn, PPF did not differ between groups. The bar graphs on the right are from averaged post-HFS data, reinforcing conclusions from the curve graphs on the left $\left({ }^{*} p<0.05\right)$. Values expressed as mean \pm standard error.

does not result in presynaptic impairments. Srivareerat et al. (2011) have also assessed chronic Nic's effects in the $A \beta$ infusion model of Alzheimer's disease. The study has shown that chronic Nic prevents CA1 LTP deficits in A $\beta$-infused rats. Srivareerat et al. (2011) have additionally found that Nic prevents spatial learning and short-term memory impairments from $A \beta$ infusion. Besides, Nic neither enhanced nor decreased HFS-induced LTP in non$A \beta$-infused rats, in agreement with our work. Subsequently, Ardiles et al. (2012) have shown that decreases in recognition memory are correlated with postsynaptic deficits in the Schaffer collateral-CA1 pathway in Octodon degus, a rodent species known for spontaneously developing pathological signs of Alzheimer's disease.

Hypofunction of classical cholinergic markers (e.g., ChAT, ACh, and ACh receptors) throughout the basal forebrain, neocortex, and hippocampus, has been related to the progressive cognitive deficit in early Alzheimer's (Schliebs and Arendt, 2006, 2011; Hernandez and Dineley, 2012). Such changes have led to the cholinergic hypothesis of memory dysfunction (Bartus, 2000; Craig et al., 2011). In fact, enhancing cholinergic function by continued use of cholinesterase inhibitor drugs is the currently accepted treatment against the onset of Alzheimer's disease (Anand et al., 2014). However, several studies indicate that directly activating
A

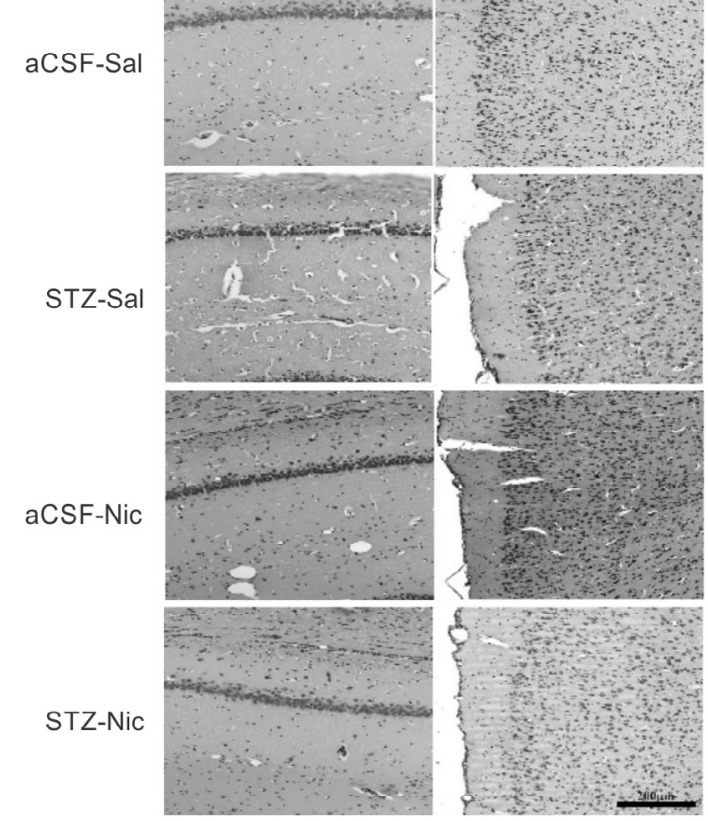

B

aCSF-Sal (n=5) $\square$ STZ-Sal (n=6)

aCSF-Nic $(n=5)$

STZ-Nic $(n=5)$
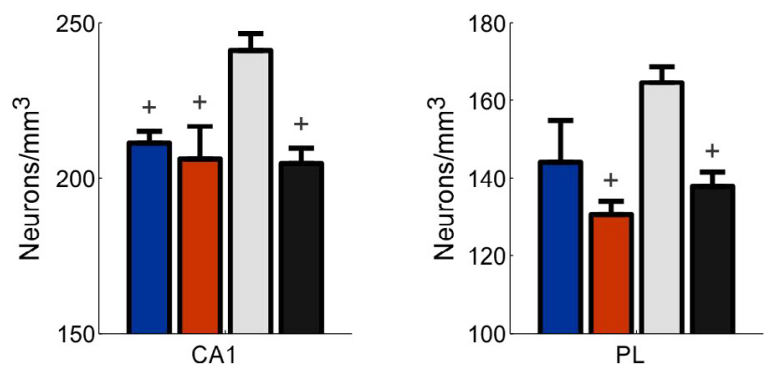

PL

Fig. 6. Cell density in $\mathrm{CA} 1$ and the prelimbic $(P L)$ region of the medial prefrontal cortex (mPFC) following streptozotocin (STZ). (A) Representative $C A 1$ and $m P F C$ images from each experimental group. (B) STZ per se did not alter CA1 or mPFC cell densities. Nicotine (Nic) alone increased CA1 cell density when analyzing STZ-untreated groups. The mPFC also showed increased neuronal density in the aCSF-Nic group when compared to the STZ-Sal and STZ-Nic groups $\left({ }^{ \pm} p<0.05\right.$ vs. aCSF-Nic). Values expressed as mean \pm standard error.

the $\alpha 7$ and $\alpha 4 \beta 2$ subtypes of nAChR can improve both synaptic transmission and cognition (Wallace and Porter, 2011; Kroker et al., 2011; Ondrejcak et al., 2012). Thus, direct nAChR targeting has emerged as an alternative approach for treating Alzheimer's disease, as well as other cognitive disorders (Haydar and Dunlop, 2010). The agonism of $\alpha 7$ and $\alpha 4 \beta 2$ nAChR subtypes can be among the Nic-mediated changes we observed here. In fact, chronic Nic exposure may trigger a cascade of events involving nicotinic receptor desensitization followed by long-lasting up-regulation (Gould and Leach, 2014; Markou, 2008; Dani and Bertrand, 2007; DiFranza and Wellman, 2007). We suggest that these processes could compensate for the disrupted cholinergic transmis- 
sion in icv-STZ, thus ameliorating mnemonic and synaptic plasticity deficits.

Finally, we also found that Nic per se may exert neuroprotective effects in CA1 against age-related cell loss. Saxena et al. (2011) have shown that a 14-day chronic Nic treatment in icv-STZ-treated animals avoids mitochondrial dysfunctions and caspase- 3 activity, evidencing the Nic protective influence against apoptosisrelated processes. Our findings, together with those from Srivareerat et al. (2011), are in agreement with multiple reports on Nic neuroprotective roles (Fujii and Sumikawa, 2001; Picciotto and Zoli, 2002; Liu and Zhao, 2004; Unger et al., 2006; Poorthuis et al., 2009). In addition, it has been shown that neuroprotection is blocked by nAChR antagonists (Akaike et al., 2010), and that nicotinic receptors can modulate mnemonic processes involving $\mathrm{ACh}$ release and $\mathrm{Ca}^{2+}$ homeostasis (Séguéla et al., 1993; McGehee et al., 1995).

In summary, we show that Nic effectively prevents recognition memory and hippocampal-prefrontal LTP deficits from icv-STZ. Targeting $\mathrm{nAChR}$ might represent a useful strategy against the cognitive deficits of prodromal Alzheimer's disease, but more studies are needed to identify nicotinic regimes devoid of addictive side effects, either using Nic or other nicotinic drugs. Moreover, as suggested by the distinct LTP and PPF effects to icv-STZ, each form of synaptic plasticity might undergo particular perturbations as Alzheimer's disease progresses, which deserves detailed investigation.

\section{FINANCIAL DISCLOSURES}

None of the authors have any potential or actual financial interests or conflict of interest.

Acknowledgments-We thank Renata Caldo Scandiuzzi and Antonio Renato Meirelles e Silva for their technical support. Further, we thank Calvin K. Young and Christopher Kushmerick for valuable comments. This work was supported by grants from CNPq [\#161239/2011-0; \#2012/23918-0], São Paulo Research Foundation (FAPESP) [\#2014/18211-0; \#2015/25275-8], and CNPq/MS/SCTIE/DECIT [\#466995/2014-8].

\section{REFERENCES}

Abercrombie M (1946) Estimation of nuclear population from microtome sections. Anatom Rec 94:239-247.

Agrawal R, Tyagi E, Shukla R, Nath C (2011) Insulin receptor signaling in rat hippocampus: a study in stz (icv) induced memory deficit model. Eur Neuropsychopharmacol 21(3):261-273.

Akaike A, Takada-Takatori Y, Kume T, Izumi Y (2010) Mechanisms of neuroprotective effects of nicotine and acetylcholinesterase inhibitors: role of alpha4 and alpha7 receptors in neuroprotection. J Mol Neurosci 40(1-2):211-216.

Alkadhi KA, Srivareerat M, Tran TT (2010) Intensification of long-term memory deficit by chronic stress and prevention by nicotine in a rat model of Alzheimer's disease. Mol Cell Neurosci 45 (3):289-296.

Anand R, Gill KD, Mahdi AA (2014) Therapeutics of Alzheimer's disease: past, present and future. Neuropharmacology 76:27-50.

Andrade-Valença LP, Valença MM, Velasco TR, Carlotti Jr CG, Assirati JA, Galvis-Alonso OY, Neder L, Cendes F, Leite JP (2008) Mesial temporal lobe epilepsy: clinical and neuropathologic findings of familial and sporadic forms. Epilepsia 49 (6): 1046-1054.

Ardiles AO, Tapia-Rojas CC, Mandal M, Alexandre F, Kirkwood A, Inestrosa NC, Palacios AG (2012) Postsynaptic dysfunction is associated with spatial and object recognition memory loss in a natural model of Alzheimer's disease. Proc Natl Acad Sci USA 109(34):13835-13840.

Arendt T (2009) Synaptic degeneration in Alzheimer's disease. Acta Neuropathol 118(1):167-179.

Auld DS, Kornecook TJ, Bastianetto S, Quirion R (2002) Alzheimer's disease and the basal forebrain cholinergic system: relations to beta-amyloid peptides, cognition, and treatment strategies. Prog Neurobiol 68(3):209-245.

Barilar JO, Knezovic A, Grünblatt E, Riederer P, Salkovic-Petrisic M (2015) Nine-month follow-up of the insulin receptor signalling cascade in the brain of streptozotocin rat model of sporadic Alzheimer's disease. J Neural Transm 122(4):565-576.

Barker GR, Banks PJ, Scott H, Ralph GS, Mitrophanous KA, Wong LF, Bashir ZI, Uney JB, Warburton EC (2017) Separate elements of episodic memory subserved by distinct hippocampal-prefrontal connections. Nat Neurosci 20(2):242-250.

Bartus RT (2000) On neurodegenerative diseases, models, and treatment strategies: lessons learned and lessons forgotten a generation following the cholinergic hypothesis. Exp Neurol 163 (2):495-529.

Bevins RA, Besheer J (2006) Object recognition in rats and mice: a one-trial non-matching -to-sample learning task to study 'recognition memory'. Nat Protoc 1(3):1306-1311.

Bliss TV, Collingridge GL (1993) A synaptic model of memory: longterm potentiation in the hippocampus. Nature 361(6407):31-39.

Blokland A, Jolles J (1993) Spatial learning deficit and reduced hippocampal ChAT activity in rats after an ICV injection of streptozotocin. Pharmacol Biochem Behav 44:491-494.

Blot K, Kimura S, Bai J, Kemp A, Manahan-Vaughan D, Giros B, Tzavara E, Otani S (2015) Modulation of hippocampus-prefrontal cortex synaptic transmission and disruption of executive cognitive functions by MK-801. Cereb Cortex 25(5):1348-13461.

Chakroborty S, Kim J, Schneider C, Jacobson C, Molgó J, Stutzmann GE (2012) Early presynaptic and postsynaptic calcium signaling abnormalities mask underlying synaptic depression in presymptomatic Alzheimer's disease mice. J Neurosci 32 (24):8341-8353.

Changeux JP (2010) Nicotine addiction and nicotinic receptors: lessons from genetically modified mice. Nat Rev Neurosci 11 (6):389-401.

Chen Y, Liang Z, Blanchard J, Dai CL, Sun S, Lee MH, Grundke-labal I, lqbal K, Liu F, Gong CX (2013) A non-transgenic mouse model (icv-STZ mouse) of Alzheimer's disease: similarities to and differences from the transgenic model (3xTg-AD mouse). Mol Neurobiol 47(2):711-725.

Citri A, Malenka RC (2008) Synaptic plasticity: multiple forms, functions, and mechanisms. Neuropsychopharmacology 33:18-41.

Clark JK, Furgerson M, Crystal JD, Fechheimer M, Furukawa R, Wagner JJ (2015) Alterations in synaptic plasticity coincide with deficits in spatial working memory in presymptomatic 3xTg-AD mice. Neurobiol Learn Mem 125:152-162.

Craig LA, Hong NS, McDonald RJ (2011) Revisiting the cholinergic hypothesis in the development of Alzheimer's disease. Neurosci Biobehav Rev 35(6):1397-1409.

Dani JA, Bertrand D (2007) Nicotinic acetylcholine receptors and nicotinic cholinergic mechanisms of the central nervous system. Annu Rev Pharmacol Toxicol 47:699-729.

de la Monte SM (2014) Type 3 diabetes is sporadic Alzheimer's disease: mini-review. Eur Neuropsychopharmacol 24 (12):1954-1960.

de la Monte SM, Tong M (2014) Brain metabolic dysfunction at the core of Alzheimer's disease. Biochem Pharmacol 88(4):548-559.

DiFranza JR, Wellman RJ (2007) Sensitization to nicotine: how the animal literature might inform future human research. Nicotine Tob Res 9(1):9-20. 
Espinosa J, Rocha A, Nunes F, Costa MS, Schein V, Kazlauckas V, Kalinine E, Souza DO, Cunha RA, Porciúncula LO (2013) Caffeine consumption prevents memory I mpairment, neuronal damage, and adenosine $\mathrm{A} 2 \mathrm{~A}$ receptors upregulation in the hippocampus of a rat model of sporadic dementia. J Alzheimers Dis 34(2):509-518.

Fisher A (2012) Cholinergic modulation of amyloid precursor protein processing with emphasis on M1 muscarinic receptor: perspectives and challenges in treatment of Alzheimer's disease. J Neurochem 120(1):22-33.

Frölich L, Blum-Degen D, Bernstein HG, Engelsberger S, Humrich J, Laufer S, et al. (1998) Brain insulin and insulin receptors in aging and sporadic Alzheimer's disease. J Neural Transm 105:423-438.

Fujii S, Sumikawa K (2001) Acute and chronic nicotine exposure reverse age-related declines in the induction of long-term potentiation in the rat hippocampus. Brain Res 894(2):347-353.

Gould TJ, Leach PT (2014) Cellular, molecular, and genetic substrates underlying the impact of nicotine on learning. Neurobiol Learn Mem 107:108-132.

Grieb P (2016) Intracerebroventricular streptozotocin injections as a model of Alzheimer's disease: in search of a relevant mechanism. Mol Neurobiol 53(3):1741-1752.

Grünblatt E, Salkovic-Petrisic M, Osmanovic J, Riederer P, Hoyer S (2007) Brain insulin system dysfunction in streptozotocin intracerebroventricularly treated rats generates hyperphosphorylated tau protein. J Neurochem 101:757-770.

Haydar SN, Dunlop J (2010) Neuronal nicotinic acetylcholine receptors - targets for the development of drugs to treat cognitive impairment associated with schizophrenia and Alzheimer's disease. Curr Top Med Chem 10:144-152.

Hernandez CM, Dineley KT (2012) A7 nicotinic acetylcholine receptors in Alzheimer's disease: neuroprotective, neurotrophic or both? Curr Drug Targets 13(5):613-622.

Hoyer S (1998) Is sporadic Alzheimer disease the brain type of noninsulin dependent diabetes mellitus? A challenging hypothesis. J Neural Transm 105:415-422.

Hoyer S (2002) The brain insulin signal transduction system and sporadic (type II) Alzheimer disease: an update. J Neural Transm (Vienna) 109(3):341-360.

Hoyer S (2004) Glucose metabolism and insulin receptor signal transduction in Alzheimer disease. Eur $J$ Pharmacol 490:115-125.

Hoyer S, Lannert H (2007) Long-term abnormalities in brain glucose energy metabolism after inhibition of the neuronal insulin receptor: implication of tau-protein. J Neural Transm 72:195-202.

Jadhav SP, Rothschild G, Roumis DK, Frank LM (2016) Coordinated excitation and inhibition of prefrontal ensembles during awake hippocampal sharp-wave ripple events. Neuron 90(1):113-127.

Kandratavicius L, Monteiro MR, Assirati Jr JA, Carlotti Jr CG, Hallak JE, Leite JP (2013) Neurotrophins in mesial temporal lobe epilepsy with and without psychiatric comorbidities. J Neuropathol Exp Neurol 72(11):1029-1042.

Kandratavicius L, Hallak JE, Carlotti Jr CG, Assirati Jr JA, Leite JP (2014) Hippocampal expression of heat shock proteins in mesial temporal lobe epilepsy with psychiatric comorbidities and their relation to seizure outcome. Epilepsia 55(11):1834-1843.

Kenney JW, Gould TJ (2008) Modulation of hippocampus-dependent learning and synaptic plasticity by nicotine. Mol Neurobiol 38 (1):101-121.

Kroker KS, Rast G, Rosenbrock H (2011) Differential effects of subtype-specific nicotinic acetylcholine receptor agonists on early and late hippocampal LTP. Eur J Pharmacol 671(1-3):26-32.

Lambe EK, Picciotto MR, Aghajanian GK (2003) Nicotine induces glutamate release from thalamocortical terminals in prefrontal cortex. Neuropsychopharmacology 28(2):216-225.

Lannert H, Hoyer S (1998) Intracerebroventricular administration of streptozotocin causes long-term diminutions in learning and memory abilities and in cerebralenergy metabolism in adult rats. Behav Neurosci 112:1199-1208.
Laroche S, Jay TM, Thierry AM (1990) Long-term potentiation in the prefrontal cortex following stimulation of the hippocampal CA1/subicular region. Neurosci Lett 114(2):184-190.

Laroche S, Davis S, Jay TM (2000) Plasticity at hippocampal to prefrontal cortex synapses: dual roles in working memory and consolidation. Hippocampus 10(4):438-446.

Leiser SC, Bowlby MR, Comery TA, Dunlop J (2009) A cog in cognition: how the alpha 7 nicotinic acetylcholine receptor is geared towards improving cognitive deficits. Pharmacol Ther 122 (3):302-311.

Lester-Coll N, Rivera EJ, Soscia SJ, Doiron K, Wands JR, de la Monte SM (2006) Intracerebral streptozotocin model of type 3 diabetes: relevance to sporadic Alzheimer's disease. J Alzheimers Dis 9:13-33.

Levin ED (2012) A7-Nicotinic receptors and cognition. Curr Drug Targets 13(5):602-606.

Liu Q, Zhao B (2004) Nicotine attenuates beta-amyloid peptideinduced neurotoxicity, free radical and calcium accumulation in hippocampal neuronal cultures. Br J Pharmacol 141:746-754.

Lopes-Aguiar C, Romcy-Pereira RN, Escorsim-Szawka R, GalvisAlonso OY, Anselmo- Franci JA, Pereira Leite J (2008) Muscarinic acetylcholine neurotransmission enhances the latephase of long-term potentiation in the hippocampal-prefrontal cortex pathway of rats in vivo: a possible involvement of monoaminergic systems. Neuroscience 153:1309-1319.

Lopes-Aguiar C, Bueno-Junior LS, Ruggiero RN, Romcy-Pereira RN, Leite JP (2013) NMDA receptor blockade impairs the muscarinic conversion of sub-threshold transient depression into long-lasting LTD in the hippocampus-prefrontal cortex pathway in vivo: correlation with $\gamma$ oscillations. Neuropharmacology 65:143-155.

Maingret N, Girardeau G, Todorova R, Goutierre M, Zugaro M (2016) Hippocampo-cortical coupling mediates memory consolidation during sleep. Nat Neurosci 19(7):959-964.

Markou A (2008) Review. Neurobiology of nicotine dependence. Philos Trans R Soc Lond B Biol Sci 363(1507):3159-3168.

McGehee DS, Heath MJ, Gelber S, Devay P, Role LW (1995) Nicotine enhancement of fast excitatory synaptic transmission in CNS by presynaptic receptors. Science 269:1692-1696.

Morgen K, Frölich L (2015) The metabolism hypothesis of Alzheimer's disease: from the concept of central insulin resistance and associated consequences to insulin therapy. $J$ Neural Transm 122(4):499-504.

Ondrejcak T, Wang Q, Kew JN, Virley DJ, Upton N, Anwyl R, Rowan MJ (2012) Activation of $\alpha 7$ nicotinic acetylcholine receptors persistently enhances hippocampal synaptic transmission and prevents Aß-mediated inhibition of LTP in the rat hippocampus. Eur J Pharmacol 677(1-3):63-70.

Paxinos G, Watson C (2007) The rat brain in stereotaxic coordinates. London: Academic Press. p. 462.

Picciotto MR, Zoli M (2002) Nicotinic receptors in aging and dementia. J Neurobiol 53(4):641-655.

Poorthuis RB, Mansvelder HD (2013) Nicotinic acetylcholine receptors controlling attention: behavior, circuits and sensitivity to disruption by nicotine. Biochem Pharmacol 86(8):1089-1098.

Poorthuis RB, Goriounova NA, Couey JJ, Mansvelder HD (2009) Nicotinic actions on neuronal networks for cognition: general principles and long-term consequences. Biochem Pharmacol 78 (7):668-676.

Prickaerts J, Fahrig T, Blokland A (1999) Cognitive performance and biochemical markers in septum, hippocampus and striatum of rats after an i.c.v. injection of streptozotocin: a correlation analysis. Behav Brain Res 102(1-2):73-88.

Rodrigues GR, Kandratavicius L, Peixoto-Santos JE, Monteiro MR, Gargaro AC, Geraldi Cde V, Velasco TR, Leite JP (2015) Increased frequency of hippocampal sclerosis ILAE type 2 in patients with mesial temporal lobe epilepsy with normal episodic memory. Brain 138(Pt 6):e359.

Salkovic-Petrisic M, Hoyer S (2007) Central insulin resistance as a trigger for sporadic Alzheimer-like pathology: an experimental approach. J Neural Transm Suppl 72:217-233. 
Salkovic-Petrisic M, Osmanovic J, Grünblatt E, Riederer P, Hoyer S (2009) Modeling sporadic Alzheimer's disease: the insulin resistant brain state generates multiple long- term morphobiological abnormalities including hyperphosphorylated tau protein and amyloid-beta. J Alzheimers Dis 18(4):729-750.

Salkovic-Petrisic M, Osmanovic-Barilar J, Brückner MK, Hoyer S, Arendt T, Riederer P (2011) Cerebral amyloid angiopathy in streptozotocin rat model of sporadic Alzheimer's disease: a longterm follow up study. J Neural Transm 118:765-772.

Sancheti H, Akopian G, Yin F, Brinton RD, Walsh JP, Cadenas E (2013) Age-dependent modulation of synaptic plasticity and insulin mimetic effect of lipoic acid on a mouse model of Alzheimer's disease. PLoS One 8(7):e69830.

Santos TO, Mazucanti CH, Xavier GF, Torrão AS (2012) Early and late neurodegeneration and memory disruption after intracerebroventricular streptozotocin. Physiol Behav 107 (3):401-413.

Saxena G, Patro IK, Nath C (2011) ICV STZ induced impairment in memory and neuronal mitochondrial function: a protective role of nicotinic receptor. Behav Brain Res 224(1):50-57.

Scheff SW, Price DA, Schmitt FA, Mufson EJ (2006) Hippocampal synaptic loss in early Alzheimer's disease and mild cognitive impairment. Neurobiol Aging 27(10):1372-1384.

Schliebs R, Arendt T (2006) The significance of the cholinergic system in the brain during aging and in Alzheimer's disease. $J$ Neural Transm (Vienna) 113(11):1625-1644.

Schliebs R, Arendt T (2011) The cholinergic system in aging and neuronal degeneration. Behav Brain Res 221(2):555-563.

Séguéla P, Wadiche J, Dineley-Miller K, Dani JA, Patrick JW (1993) Molecular cloning, functional properties, and distribution of rat brain alpha 7: a nicotinic cation channel highly permeable to calcium. J Neurosci 13(2):596-604.

Shoham S, Bejar C, Kovalev E, Schorer-Apelbaum D, Weinstock M (2007) Ladostigil prevents gliosis, oxidative-nitrative stress and memory deficits induced by intracerebroventricular injection of streptozotocin in rats. Neuropharmacology 52(3):836-843.

Shonesy BC, Thiruchelvam K, Parameshwaran K, Rahman EA, Karuppagounder SS, Huggins KW, Pinkert CA, Amin R, Dhanasekaran M, Suppiramaniam V (2012) Central insulin resistance and synaptic dysfunction in intracerebroventricularstreptozotocin injected rodents. Neurobiol Aging 33(2). 4305.e543018.e18.

Spellman T, Rigotti M, Ahmari SE, Fusi S4, Gogos JA, Gordon JA (2015) Hippocampal- prefrontal input supports spatial encoding in working memory. Nature 522(7556):309-314.

Srivareerat M, Tran TT, Salim S, Aleisa AM, Alkadhi KA (2011) Chronic nicotine restores normal $A \beta$ levels and prevents short- term memory and E-LTP impairment in $A \beta$ rat model of Alzheimer's disease. Neurobiol Aging 32(5):834-844.

Takeuchi T, Duszkiewicz AJ, Morris RG (2013) The synaptic plasticity and memory hypothesis: encoding, storage and persistence. Philos Trans R Soc Lond B Biol Sci 369(1633):20130288.

Takita M, Izaki Y, Jay TM, Kaneko H, Suzuki SS (1999) Induction of stable long-term depression in vivo in the hippocampal-prefrontal cortex pathway. Eur J Neurosci 11(11):4145-4148.

Takita M, Fujiwara SE, Izaki Y (2013) Functional structure of the intermediate and ventral hippocampo-prefrontal pathway in the prefrontal convergent system. J Physiol Paris 107(6):441-447.

Taylor CJ, Ohline SM, Moss T, Ulrich K, Abraham WC (2016) The persistence of long-term potentiation in the projection from ventral hippocampus to medial prefrontal cortex in awake rats. Eur $\mathrm{J}$ Neurosci 43(6):811-822.

Unger C, Svedberg MM, Yu WF, Hedberg MM, Nordberg A (2006) Effect of subchronic treatment of memantine, galantamine, and nicotine in the brain of Tg2576 (APPswe) transgenic mice. J Pharmacol Exp Ther 317:30-36.

Utsuki T, Shoaib M, Holloway HW, Ingram DK, Wallace WC, Haroutunian V, Sambamurti K, Lahiri DK, Greig NH (2002) Nicotine lowers the secretion of the Alzheimer's amyloid betaprotein precursor that contains amyloid beta-peptide in rat. $J$ Alzheimers Dis 4(5):405-415.

Wallace TL, Bertrand D (2013) Importance of the nicotinic acetylcholine receptor system in the prefrontal cortex. Biochem Pharmacol 85(12):1713-1720.

Wallace TL, Porter RH (2011) Targeting the nicotinic alpha7 acetylcholine receptor to enhance cognition in disease. Biochem Pharmacol 82(8):891-903.

Warburton EC, Barker GR, Brown MW (2013) Investigations into the involvement of NMDA mechanisms in recognition memory. Neuropharmacology 74:41-47.

Watson G, Craft S (2003) The role of insulin resistance in the pathogenesis of Alzheimer's disease: implications for treatment. CNS Drugs 17(1):27-45.

Wolf DC, Bueno-Júnior LS, Lopes-Aguiar C, Do.Val.Da Silva RA, Kandratavicius L, Leite JP (2015) The frequency of spontaneous seizures in rats correlates with alterations in sensorimotor gating, spatial working memory, and parvalbumin expression throughout limbic regions. Neuroscience 312:86-98.

Xu ZP, Li L, Bao J, Wang ZH, Zeng J, Liu EJ, Li XG, Huang RX, Gao D, Li MZ, Zhang Y, Liu GP, Wang JZ (2014) Magnesium protects cognitive functions and synaptic plasticity in streptozotocininduced sporadic Alzheimer's model. PLoS One 9(9):e108645. 